\title{
Constructing the Medieval Sermon, Edited by Roger Andersson
}

\section{G. Matteo Roccati}

\section{(2) OpenEdition}

Journals

Édition électronique

URL : http://journals.openedition.org/studifrancesi/5862

DOI : ERREUR PDO dans /localdata/www-bin/Core/Core/Db/Db.class.php L.34 : SQLSTATE[HY000]

[2006] MySQL server has gone away

ISSN : 2427-5856

Éditeur

Rosenberg \& Sellier

Édition imprimée

Date de publication : 1 mai 2011

Pagination : 146-147

ISSN : 0039-2944

\section{Référence électronique}

G. Matteo Roccati, «Constructing the Medieval Sermon, Edited by Roger Andersson », Studi Francesi [En ligne], 163 (LV | I) | 2011, mis en ligne le 30 novembre 2015, consulté le 07 janvier 2021. URL : http:// journals.openedition.org/studifrancesi/5862 ; DOI : https://doi.org/10.4000/studifrancesi.5862

Ce document a été généré automatiquement le 7 janvier 2021.

\section{(c)}

Studi Francesi è distribuita con Licenza Creative Commons Attribuzione - Non commerciale - Non opere derivate 4.0 Internazionale. 


\title{
Constructing the Medieval Sermon, Edited by Roger Andersson
}

\author{
G. Matteo Roccati
}

\section{RÉFÉRENCE}

Constructing the Medieval Sermon, Edited by Roger ANDERSSON, Turnhout, Brepols, 2007

(«Sermo: Studies on Patristic, Medieval, and Reformation Sermons and Preaching», 6), pp. XIV-334.

1 Le volume rassemble treize contributions, présentées lors d'une rencontre qui s'est tenue à Stockholm en 2004. On retiendra plus particulièrement dans le cadre de la rassegna les suivantes.

2 Yuichi AKAE, Between "artes praedicandi" and Actual Sermons: Robert of Basevorn's "Forma praedicandi" and the Sermons of John Waldeby, OESA, pp.9-31, établit une comparaison précise entre la structure d'un sermon de John Waldeby, augustin du XIV ${ }^{\mathrm{e}}$ siècle, et les techniques de prédication prônées par Basevorn. Il montre que sont appliquées les consignes de ce dernier et constate que le sermon relève de la forme «moderne» de la prédication (non pas essentiellement commentaire de l'écriture, comme dans la forme «ancienne», mais développement construit, à partir d'un verset de l'Ecriture, traitant d'une question déterminée); le sermon témoigne, bien qu'avec des différences, de la diffusion de modèles émanant de l'université de Paris.

Riccardo QUINTO, Peter the Chanter and the 'Miscellanea del Codice del Tesoro' (Etymology as a Way for Constructing a Sermon), pp.33-81, examine avec soin les sources d'un sermon du Codice del Tesoro (IX) de la Biblioteca Antoniana à Padoue et conclut que le sermon est issu du milieu des maitres séculiers parisiens de la fin du XII ${ }^{\mathrm{e}}$ siècle, un milieu important pour comprendre l'évolution de la théologie et de la pastorale.

Silvia SERVENTI, Did Giordano da Pisa Use the "Distinctiones" of Nicolas Gorran?, pp. 83-116, compare les sermons de Giordano avec l'ouvrage de Nicolas Gorran, prieur du couvent dominicain de Saint-Jacques et confesseur de Philippe IV, afin d'établir une dépendance 
éventuelle (en appendice, pp.95-116, la description de trois manuscrits, la table des Distinctiones, et l'édition de trois entrées).

5 Christoph BURGER, Preaching for Members of the University in Latin, for Parishioners in French: Jean Gerson (1363-1429) on 'Blessed are they that mourn', pp. 207-220, analyse les deux sermons Beati qui lugent, prêchés à un jour de distance (en 1401 ou 1402), et pointe les différences dues au fait que Gerson adapte à l'auditoire son propos (savant et rhétoriquement construit pour les universitaires, édifiant et faisant appel à l'émotion dans le sermon en langue vernaculaire).

6 Jussi HANSKA, "Uidens Iesus ciuitatem fleuit super illam»: The "Lachrymae Christi" Topos in Thirteenth-Century Sermon Literature, pp. 237-251, retrace l'histoire du topos et étudie le message qu'il délivre chez une douzaine d'auteurs.

7 Le volume comporte l'index des manuscrits et celui des noms propres. 